\title{
Methodology for Optimization of the Electric Wire Arc - Spraying Process to the Mixture of Coatings 140MXC-530AS and 140MXC- 560AS Using a Multi-objective Genetic Algorithm
}

\author{
Héctor F. Rojas ( $\square$ hector.rojas@unilibre.edu.co) \\ Universidad Libre https://orcid.org/0000-0001-8725-3008 \\ María A. Guzmán \\ Universidad Nacional de Colombia \\ Oscar E. Luna \\ Universidad Libre \\ Diana F. Aragón \\ CME - SENA
}

\section{Original Article}

Keywords: Coating, Genetic Algorithm, Optimization, Thermal Spraying

Posted Date: October 12th, 2020

DOI: https://doi.org/10.21203/rs.3.rs-88805/v1

License: (a) (1) This work is licensed under a Creative Commons Attribution 4.0 International License. Read Full License 


\section{Abstract}

The Corporation of Science and Technology for the Development of the Maritime and Fluvial Shipbuilding Industry COTECMAR has been using for more than 4 years the process of electric arc thermal projection with commercial materials such as 530AS, 560AS and $140 \mathrm{MXC}$ to mitigate corrosion phenomena and wear of the different devices that make up the boats. The problem lies in mixing these materials (140MXC-530AS and 140MXC-560AS) to produce dissimilar coatings, making it more difficult to optimize the process, whose problem lies in the parameterization of the arc-beam thermal imaging equipment. In the first phase of the project, a Taguchi $L_{9}$ $\left(3^{4-2}\right)$ model (fractional factorial orthogonal arrangement) was used to produce the coatings, taking into account the projection parameters of the equipment such as current (A), voltage (V) Primary air pressure (Pp) and secondary air pressure (Ps), which were considered as input variables or experiments for the optimization process. Subsequently the coatings were characterized by techniques such as Scanning Electron Microscopy (SEM) and microhardness to take these data as attributes or output of results in order to obtain the minimization of the size of the projected particles (corrosion) and the microhardness maximization of the coatings (wear). Symbolic regression was used as a technique for obtaining the mathematical models (objective functions), which was done through the "Eureqa Formulize-Desktop" program, because it is considered very complex the modeling of all input variables by conventional mathematical methods. The adaptation of the NSGA-II Multi-Objective Genetic Algorithm was performed through a structured programming in "Matlab", being able to verify that the optimal Pareto fronts obtained in the runs with this Algorithm meet the requirements of the objective functions which are related with the attributes of the selected coatings.

\section{Introduction}

The electric wire arc - spraying process is one of the most used industrial techniques in the process of thermal spraying for the recovery of mechanical components that have suffered deterioration due to the conditions of wear and corrosion. The coatings used in this technique are solid wires (Fig. 1) which are fused by the interaction of the electrical parameters of the thermal projection equipment (current and voltage).

The air pressure used in the equipment projects the molten material into drops, which are deposited on a previously prepared surface called the substrate forming the layers of the coating (Fig. 2).

Optimization consists in the selection of a better alternative that results in the search for a minimum or a maximum, locating this optimum through a mathematical structure that can be by descriptive models, that simulate the behavior of a device or system, or by prescriptive models that allow to indicate the course of action or the best design, fulfilling with the premise of the optimization as the best result of a problem [3].

Within the optimization practices, there are two branches: 1 ) the problem of how to properly model the system under study and 2) how to solve the model [4]. These authors agree that the optimization problems contain the following fundamental elements: 1) Objective Function; 2) Design Variables and 3) Restrictions. According to the above, the classification of optimization problems can be: according to the form of $f(x)$, the number of constraints, their dimensionality, the probabilistic nature of the problem and the continuity or not of the decision variables [3]. Now, the classification of methods of resolution to these problems are given by mathematical calculation, search techniques and / or convergence techniques of solutions [4]. In this way, the classic problem of optimization consists in determining or choosing, among all possible solution alternatives, the one that has a greater degree of desirability for the decision maker, which is the optimal solution.

In this case, the problem of interest to optimize is focused on the electric wire arc - spraying process, which is part of one of the many options that may exist for the production of coatings [5] ranging from materials conventional such as carbon steel (530AS) and stainless steel (560AS) commercially economic and functional for common applications, to materials such nanostructures as socalled nano-compounds (140MXC) that can become raw material of high cost with special properties in their chemical composition and mechanical properties [6]. The production of the coatings provides the surfaces with protection against corrosion and wear; also, improves the performance of the substrate or component when they are used as a thermal barrier, allowing the restoration and repair of parts or components [7].

The equipment works through the manual configuration, by an operator, of the projection parameters (voltage, current, primary air pressure and secondary air pressure) and taking into account influential aspects such as: projection distance, velocity of projection, spray angle [8]. With this approach, it is implicitly assumed that the criterion in which the preferences of the decision maker (operator

Page 2/20 
of the equipment) are collected can be represented mathematically through a function, called "objective function", that will allow to order the possible decisions by means of the assignment to each one of an index of desirability; so, multi-objective programming can be considered the first stage of a decisional process [9].

Thanks to this and to the number of problems that often arise, a variety of multi-objective optimization algorithms are found, such as: - PAES (Pareto Archived Evolution Strategy), - PESA (Pareto Envelope Based Selection Algorithm), - APA (Adaptive Pareto Algorithm) [10]; and the most used in recent times as: -SPEA II [11] and - NSGA II (Nondominated Sorting Genetic Algorithm) [12].

In the case of the NSGA-II algorithm used in this work, it is an improved version of its predecessor (NSGA), from which it inherited its main structure but including features that solve three aspects: 1) non-dominated ordering and computational complexity, 2) the absence of elitism and 3) the need to specify additional parameters for the preservation of diversity in the Pareto front [13]. In the software and programs used in optimization problems, considered as a specific derivation of languages or computing environments, the present investigation based its development on the Eureqa Formulize - Desktop program to obtain the objective functions and the MATLAB R2010a program for analysis and optimization of functions.

\section{Experimental Details}

\subsection{Production of the mixture of coatings}

For the production of 140MXC-530AS and 140MXC-560AS coatings, the traditional EUTECTIC / EUTRONIC ARC SPRAY 4 equipment of the traditional Push / Pull type (Figure 3: a) Side view, b) Front view and c) Detail of the spray gun) was used, in which the wires (coatings) are pushed by a motor located near the coil and in turn pulled by a second motor located in the gun. The operating characteristics of the equipment are: Electric current from 0 to $350 \mathrm{~A}$, Voltage from 0 to $50 \mathrm{~V}$ Dc, Projection air pressure from 0 to 5.5 bar and Atomization air at $1.23 \mathrm{~m}^{3} / \mathrm{min}$. Table 1 indicates the operating conditions of the electric wire arc spraying equipment according to its manufacturer and the minimum and maximum values at which the projection parameters can be configured; current works on 2 levels and voltage 5 (discrete variables), while pressures primary and secondary air rely on the operator to make adjustments (continuous variables). Figure 4 shows the unit operating console for the condition of the projection parameters.

Table 1. Operating conditions of the equipment System Eutectic / Eutronic Arc Spray 4

\begin{tabular}{|lllll|}
\hline Variables & Precision & Level & min & $\max$ \\
\hline Current (A) & 20 & 1 & 0 & 200 \\
\cline { 2 - 4 } & & 2 & 200 & 400 \\
Voltage (V) & 2 & 1 & 0 & 10 \\
\cline { 2 - 5 } & & 2 & 10 & 20 \\
& & 3 & 20 & 30 \\
\hline Primary air pressure (bar) & 0.2 & 4 & 30 & 40 \\
\hline Secondary air pressure (bar) & 0.2 & Adjustable & 0 & 10 \\
\hline
\end{tabular}

Tables 2 and 3 establish the projection parameters of the coatings according to the manufacturers and the values considered in the pilot test during the application respectively.

Table 2. Projection parameters of the coatings according to manufacturer 


\begin{tabular}{|llll|}
\hline Variable / Coating & 140MXC & 530AS & 560AS \\
\hline Current & $175(\mathrm{~A})$ & $100-200(\mathrm{~A})$ & $100-200(\mathrm{~A})$ \\
\hline Voltage & $29-32(\mathrm{~V})$ & $29-32(\mathrm{~V})$ & $28-30(\mathrm{~V})$ \\
\hline Pressure air & $50-70(\mathrm{psi})$ or $3.5-5(\mathrm{bar})$ & $50-70(\mathrm{psi})$ or $3.5-5(\mathrm{bar})$ & $50-60(\mathrm{psi})$ or $3.5-4.2(\mathrm{bar})$ \\
\hline Distance projection & $10(\mathrm{~cm})$ & $10-20(\mathrm{~cm})$ & $10-15(\mathrm{~cm})$ \\
\hline
\end{tabular}

Table 3. Projection parameters of the coatings in the pilot test

\begin{tabular}{|llll|}
\hline Variable / Levels & Low (1) & Medium (2) & High (3) \\
\hline Current (A) & 120 & 140 & 160 \\
\hline Voltage (V) & 28 & 30 & 32 \\
\hline Primary air pressure (Pp) (bar) & 3.4 & 4.2 & 4.8 \\
\hline Secondary air pressure (Ps) (bar) & 3.4 & 4.2 & 4.8 \\
\hline Distance Projection (cm) & 10 Constant & 10 Constant & 10 Constant \\
\hline
\end{tabular}

Table 4 shows the values configured with the Taguchi model L9 $\left(3^{4-2}\right)$ for the projection and production parameters of the coating's mixtures 140MC-530AS and 140MXC-560AS.

Table 4. Projection parameters of the coatings with the model Taguchi L9 $\left(3^{4-2}\right)$

\begin{tabular}{|llllllllll|}
\hline $\mathbf{1 4 0 M X C - 5 3 0 A S}$ & & \multicolumn{7}{c|}{ 140MXC-560AS } \\
\hline $\begin{array}{l}\text { Experiment } \\
\mathbf{N}^{\circ}\end{array}$ & $\begin{array}{l}\text { Current } \\
(\mathbf{A})\end{array}$ & $\begin{array}{l}\text { Voltage } \\
(\mathrm{V})\end{array}$ & $\begin{array}{l}\text { Primary air } \\
\text { pressure (bar) }\end{array}$ & $\begin{array}{l}\text { Secondary air } \\
\text { pressure (bar) }\end{array}$ & $\begin{array}{l}\text { Current } \\
(\mathbf{A})\end{array}$ & $\begin{array}{l}\text { Voltage } \\
\text { (V) }\end{array}$ & $\begin{array}{l}\text { Primary air } \\
\text { pressure } \\
\text { (bar) }\end{array}$ & $\begin{array}{l}\text { Secondary air } \\
\text { pressure (bar) }\end{array}$ \\
\hline $\mathbf{1}$ & 120 & 28 & 3.4 & 3.4 & 120 & 28 & 3.4 & 3.4 \\
\hline $\mathbf{2}$ & 120 & 30 & 4.2 & 4.2 & 120 & 30 & 3.8 & 3.8 \\
\hline $\mathbf{3}$ & 120 & 32 & 4.8 & 4.8 & 120 & 32 & 4.2 & 4.2 \\
\hline $\mathbf{4}$ & 140 & 28 & 4.2 & 4.8 & 140 & 28 & 3.8 & 4.2 \\
\hline $\mathbf{5}$ & 140 & 30 & 4.8 & 3.4 & 140 & 30 & 4.2 & 3.4 \\
\hline $\mathbf{6}$ & 140 & 32 & 3.4 & 4.2 & 140 & 32 & 3.4 & 3.8 \\
\hline $\mathbf{7}$ & 160 & 28 & 4.8 & 4.2 & 160 & 28 & 4.2 & 3.8 \\
\hline $\mathbf{8}$ & 160 & 30 & 3.4 & 4.8 & 160 & 30 & 3.4 & 4.2 \\
\hline $\mathbf{9}$ & 160 & 32 & 4.2 & 3.4 & 160 & 32 & 3.8 & 3.4 \\
\hline
\end{tabular}

\subsection{Characterization of coatings}

The morphological characterization and the determination of the particle size for the mixture of coatings 140MXC-530AS and $140 \mathrm{MXC}-560 \mathrm{AS}$ were carried out in the first instance by means of scanning electron microscopy (SEM). The obtained images were divided in four sectors (Figure 5) and analyzed in the program "GWYDDION", which generates a pixel contrast to the selected 
geometries and a sweep on the surface of the same, in order to measure the size particle by an autocorrelation internal statistical data obtained by the program.

The samples were indented with a diamond tip over the cross-section of the coating using a load of $200 \mathrm{~g}$ and an indentation time of 30 seconds, making three indentations in the middle zone and at the interface of the deposit with the base material (substrate) as it is shown in Figure 6.

\subsection{Obtaining the Objective Functions}

Symbolic regression is a statistical technique that seeks to deduce the pattern of a series of data or to investigate the statistical relationship between a dependent variable $(Y)$ and one or more independent variables. The result is an algebraic expression of type $Y$ $=\boldsymbol{F}(X 1, X 2, \ldots X n)$. Given the data, it will look for the pattern (algebraic expression) that identifies the behavior of these accessing all kinds of functions and algebraic combinations [14]. The program Eureqa Formulize-Desktop is software that meets the abovementioned conditions and has an online user guide where you can find all possible specifications and published by the manufacturer on how to handle this free program. For this purpose, an "Intel (R) Core (TM) i5-2410M processor, CPU @ 2.30 GHz, 8GB RAM' was used to support the computational requirement of this program as well as for the work in MATLAB.

Its handling is as follows:

a. Data Entry: According to the projection parameters (Input variables) for the production of the coatings and the results obtained from the characterization.

b. Data Preparation: The program shows the acronyms of the variables entered and a graph of behavior for each of them, with respect to the values entered

c. Definition of Search Functions: In this tab, you can define the options that the program has for obtaining mathematical expressions or models (objective functions).

d. Search Start: It is performed under the program's own genetic programming and random search configuration.

e. Results: In the tab, can be seen while the program is running, the partial results of the expressions that are being obtained and simultaneously the real time of the computational resource in the search of the expressions while converging to the definitive results.

f. Reports: When the program has made a convergence of $100 \%$, a report is generated with the list of expressions generated in descending order of quality, appreciation charts for the accuracy-approximation of the model to the data entered, the amount of occurrence of each variable in total generated equations, etc.

\subsection{Analysis of Objective Functions with MATLAB}

\subsubsection{Multi-objective optimization}

The problem raised is how to treat several objective functions at the same time, this is known as multicriteria decision [15]. Before entering the objective functions to Matlab the following aspects must be considered:

a. Optimal Selection Criteria: The optimal selection criteria can be divided into two methods for multi-objective optimization: No Dominated Classification and Pareto Optimal Classification. In both methods, before "Pareto-optimal" individuals for the current generation (Front $n+1$ ), the "Pareto-optimal" individuals of the previous generation (Front $n$ ) are added. In fact, this is the operator of elitism [16].

b. Multi-objective Optimization Algorithms: In multi-objective search and optimization problems, the quality of a candidate solution can be represented by means of a vector that groups the factors that evaluate the different objectives. The relative quality between pairs of candidate solutions is quantified using the Pareto dominance concept. A multi-objective vector $u=(u 1, u 2, \ldots$, uk) dominates another multi-objective vector $v=(v 1, v 2, \ldots, v k)$ if and only if "u" is better than " $v$ " in a target without being worse in all other [17]. In this case, it is possible to find a more efficient solution in an iteration, so that, comparatively, traditional techniques are able to achieve a better border in a shorter simulation time [13]. 


\subsubsection{Steps to run the algorithm in MATLAB}

The multi-objective algorithms require for the development of mathematical optimization methods on a population of solutions, so it has been found in the genetic algorithms a firm proposal given its diversity and reliability characteristics [18]. The steps are the following:

a. Opening the Graphical Interface (GUI): The complete program of the algorithm, is located in the "Path" MATLAB folder, then the "Current Folder" tab " Genetic_Algorithm.m " script, which is what allows the opening of the main graphical interface and activation of the buttons of the sub-routines for parameterization of the algorithm.

b. Entry of the Objective Functions: In this button "DATA_FUNCTIONS" of the GUI, this interface is the selection of the type of optimization (mono-objective or multi-objective), the icons for entering the data of the objective functions and the information of the variables to be handled. With the "Save and Exit" button, all data entered is confirmed and closes this interface, to return to the main interface and continue with the process.

c. Entry of Restrictions: If there are restrictions to consider, activate the button called "RESTRICTION_FUNCTIONS" that also appears in the "GUI" and enter the corresponding data, either by variables or by attributes to optimize, by clicking on the icon "Restriction Inactive". At the end of the information entry click on the "Save and Exit" button, noting that this button has changed color in the main interface, indicating that the restrictions are active.

d. Input of the Algorithm Data: After completing the previous steps, you proceed to enter the necessary data, typical of the algorithm, with which you will be working during your runs. Therefore, when you click on the button "DATA_ALGORITHM", in the GUI, the secondary interface containing the information about it is displayed to be filled out. When finished completing the information entry is saved by pressing the "Save and Exit" button, where it will close this secondary interface returning to the main interface to follow the process.

e. Operation of the Algorithm: Once entered all the necessary data, between functions, restrictions and operating conditions; can be given now click on the button "CALCULATE" on the main interface to run the algorithm. The whole subsequent process is left to the implemented programming so that it finds the expected results, of a simple analysis or of a multi-objective analysis of 2 objective functions.

f. Generation of Results: Once the run is finished due to some stop criterion, the mono-objective solutions are displayed in the "Command Windows" while the multi-objective analysis is shown in 2-D graphic outputs and tabulated or listed data of each graph. The results at multi-objective level are shown in MATLAB with: 1) Valid solutions to the problem in the search space, 2) Selection criteria based on the "Non-dominated classification" method and 3) Final selection criteria based on the method of "Optimal Pareto Classification".

\subsubsection{Implementation of NSGA-II}

This algorithm includes features that solve three aspects: 1) non-dominated ordering and computational complexity, 2) the absence of elitism, and 3) the need to specify additional parameters for the preservation of diversity on the front [12]. It is classified as an elitist type, since it incorporates a mechanism of preservation of dominant solutions by fronts of dominance, through several generations of a genetic algorithm; and to avoid the dependence of parameters for the dispersion in the front incorporates a calculation of stacking distance [18]. Its implementation is done as follows:

\section{a. Process of Selection, Crossing and Mutation \\ b. Calculation of the stacking distance \\ c. Selection by tournament according to stacking operator $(<c) j$ \\ d. Determination of the Final Descendant Set}

Figure 7 shows a graphical representation of how a new population is generated when the NSGA-II multi-objective genetic algorithm is used

In this case, before a generation of the algorithm is finished, a process of preselection and preservation of the elite solutions is executed, which consists of gathering the set of parent solutions and the descendants obtained through the selection, crossing and 
mutation operators. In this way the current population increases to double of the individuals of the initial population. For this it is necessary to classify the complete set in their respective fronts of dominance and to preserve the individuals that belong to the fronts of better quality. If it is not possible to enter all the alternatives of a given front, then those individuals with a smaller stacking distance given by the figure described above are eliminated [18].

\section{Results And Discussion}

Table 5 shows the results of the coatings characterization process and that were entered with the projection parameters (input variables) in the Eureqa Formulize-Desktop program to obtain the objective functions.

Table 5. Results of the characterization

\begin{tabular}{|lllll|}
\hline Experiment $\mathbf{N}^{\circ}$ & 140MXC-530AS & \multicolumn{3}{l|}{ 140MXC-560AS } \\
\cline { 2 - 5 } & Microhardness $(\mathrm{Hv})$ & $\begin{array}{l}\text { Particle Size } \\
(\mu \mathrm{m})\end{array}$ & Microhardness $(\mathrm{Hv})$ & $\begin{array}{l}\text { Particle Size } \\
(\mu \mathrm{m})\end{array}$ \\
\hline $\mathbf{1}$ & 584.53 & 155 & 186.51 & 87 \\
\hline $\mathbf{2}$ & 148.93 & 139 & 218.30 & 119 \\
\hline $\mathbf{3}$ & 164.86 & 85 & 422.86 & 133 \\
\hline $\mathbf{4}$ & 189.66 & 111 & 487.73 & 89 \\
\hline $\mathbf{5}$ & 294.76 & 79 & 121.62 & 137 \\
\hline $\mathbf{6}$ & 520.93 & 137 & 314.98 & 74 \\
\hline $\mathbf{7}$ & 351.60 & 276 & 324.60 & 89 \\
\hline $\mathbf{8}$ & 154.37 & 120 & 298.73 & 176 \\
\hline $\mathbf{9}$ & 173.30 & 134 & 202.13 & 101 \\
\hline
\end{tabular}

According to the analysis of the results of Table 5 , the optimization conditions required for the runs of the objective functions in MATLAB were established for the mixture of the coatings as shown in Table 6.

Table 6. Optimization conditions

\begin{tabular}{|lll|}
\hline Optimization Conditions Required & & \\
\hline Microhardness (Hv) 140MXC-530AS / 140MXC-560AS & Minimum & Maximum \\
\cline { 2 - 3 } & $\mathbf{5 0 0}$ & $\mathbf{8 0 0}$ \\
\hline Particle Size $(\mu \mathrm{m})$ 140MXC-530AS / 140MXC-560AS & Minimum & Maximum \\
\cline { 2 - 3 } & $\mathbf{8 0}$ & 160 \\
\hline
\end{tabular}

For the 140MXC-530AS mixture, 6 target functions were obtained for the microhardness attribute and 6 for the particle size; while for 140MXC-560AS mixture were 7 and 8 respectively. Through eq 1 (calculation of the proportional size of the solution space), the criterion for selection of the functions was established in terms of their quality, which is defined by the best proportion of the search space determined by the user (minimum and maximum value) in relation to the global search space offered by each function. Table 7 
shows the ordering of the pairing for multi-objective analysis of the best objective functions for the mixtures of $140 \mathrm{MXC}-530 \mathrm{AS}$ and $140 \mathrm{MXC}-560 \mathrm{AS}$ coatings according to the expected attributes.

$$
\begin{gathered}
\text { Formulated Value }(i)=\frac{V \operatorname{maxf}-V \operatorname{minf}}{V \max -V \min } ; \text { where }\left\{\begin{array}{l}
V \operatorname{maxf}=\text { Maximum value of the Objective function } \\
V \operatorname{minf}=\text { Minimum value of the Objective function } \\
V \max =\text { Maximum value of the optimal condition } \\
V \min =\text { Minimum value of the optimal condition }
\end{array}\right. \\
\text { Adapted from [18] }
\end{gathered}
$$

\begin{tabular}{|c|c|c|c|c|c|c|c|c|c|}
\hline \multicolumn{5}{|c|}{ 140MXC-530AS } & \multicolumn{5}{|c|}{$140 \mathrm{MXC}-560 \mathrm{AS}$} \\
\hline $\begin{array}{l}\text { Couple } \\
\mathrm{N}^{\circ}\end{array}$ & Attribute & $\begin{array}{l}\text { Mathematical } \\
\text { Selection }\end{array}$ & $\begin{array}{l}\text { Formulated } \\
\text { Value }\end{array}$ & $\begin{array}{l}\text { Function } \\
\text { No. }\end{array}$ & $\begin{array}{l}\text { Couple } \\
\mathbf{N}^{\circ}\end{array}$ & Attribute & $\begin{array}{l}\text { Mathematical } \\
\text { Selection }\end{array}$ & $\begin{array}{l}\text { Formulated } \\
\text { Value }\end{array}$ & $\begin{array}{l}\text { Function } \\
\text { No. }\end{array}$ \\
\hline \multirow[t]{2}{*}{1} & $\mathrm{Hv}$ & 1 & 5.46 & 2 & \multirow[t]{2}{*}{1} & $\mathrm{Hv}$ & 1 & 4.26 & 7 \\
\hline & $\mu \mathrm{m}$ & 1 & 5.62 & 5 & & $\mu \mathrm{m}$ & 1 & 2.82 & 5 \\
\hline \multirow[t]{2}{*}{2} & $\mathrm{Hv}$ & 2 & 5.99 & 4 & \multirow[t]{2}{*}{2} & $\mathrm{Hv}$ & 2 & 4.93 & 6 \\
\hline & $\mu \mathrm{m}$ & 2 & 5.88 & 6 & & $\mu \mathrm{m}$ & 2 & 2.87 & 6 \\
\hline \multirow[t]{2}{*}{3} & $\mathrm{Hv}$ & 3 & 9.58 & 5 & \multirow[t]{2}{*}{3} & $\mathrm{Hv}$ & 3 & 6.74 & 3 \\
\hline & $\mu \mathrm{m}$ & 3 & 6.79 & 4 & & $\mu \mathrm{m}$ & 3 & 3.43 & 7 \\
\hline
\end{tabular}

Table 7. Matching for multi-objective analysis

Table 8 shows the best objective functions obtained according to the values formulated by equation 1 for the mixtures of coatings 140MXC-530AS and 140MXC-560AS for the microhardness and particle size attributes respectively.

The objective function No 1 corresponds to the microhardness attribute for the mixture of coatings 140MXC-530AS.

The objective function No 2 corresponds to the particle size attribute for the mixture of coatings 140MXC-530AS.

The objective function No 3 corresponds to the microhardness attribute for the mixture of coatings 140MXC-560AS.

The objective function No 4 corresponds to the particle size attribute for the mixture of coatings $140 \mathrm{MXC}-560 \mathrm{AS}$.

Table 8. Objective functions of coatings mixtures 140MXC-530AS and 140MXC-560AS 


\begin{tabular}{|c|c|}
\hline $\mathbf{N}^{\circ}$ & Objective Function for mixing 140MXC-530AS / Attribute: Microhardness (Hv) \\
\hline 1 & $\begin{array}{l}10025.8717696593+45.5559873990753^{\star} A+22.2395466925751^{*} P s+21.0496919996887 * V+528.073096469254 * P^{\wedge} 2 \\
+0.184097466280761^{\star} A^{\star} P p^{\wedge} 2+-0.731839755539107^{\star} A^{\wedge} 2 / P p-5539.23800112966 * \mathrm{Pp}\end{array}$ \\
\hline $\mathbf{N}^{\circ}$ & Objective Function for mixing 140MXC-530AS / Attribute: Particle size $(\mu \mathrm{m})$ \\
\hline 2 & $\begin{array}{l}0.570621174976964+2.0297809250124^{\star} \cos (1.85931009469647+\mathrm{Ps})+1.18390307276845^{\star} \sin (5.37807343097015+\mathrm{A} \\
+\mathrm{Pp})-0.057557968428169^{*} \mathrm{Pp}-0.038324437107436^{*} \mathrm{Ps}^{\star} \cos \left(1.37568335042401^{\star} \mathrm{A}-0.65229880278333^{*} \mathrm{~V}\right)\end{array}$ \\
\hline $\mathbf{N}^{\circ}$ & Objective Function for mixing 140MXC-560AS / Attribute: Microhardness (Hv) \\
\hline 3 & $\begin{array}{l}1574.30406778521 * \mathrm{Pp}+298.150342662608 * \mathrm{Ps}+0.681797613141099 * \mathrm{~A}+550.220928526876 * \sin (\mathrm{V})+ \\
-1777.66598085211^{*} \sin (\mathrm{V}) / \mathrm{Ps}-3540.16559556089-10.3537290404493 * \mathrm{~V}-210.985961933397 * \mathrm{Pp}^{\wedge} 2\end{array}$ \\
\hline $\mathbf{N}^{\circ}$ & Objective Function for mixing 140MXC-560AS / Attribute: Particle size $(\mu \mathrm{m})$ \\
\hline 4 & $\begin{array}{l}0.0520645141336136 * V+0.0171407127971521 * V * P p^{\star} \sin (V)+-0.00248390483036672^{\star} A^{\star} \sin (V) / P s- \\
0.325491914509165-2.20407853879951 * \sin (V)-0.402194869142805^{\star} \sin \left(0.537136306307155^{\star} P^{\wedge} 2^{\star} \sin (V)^{\wedge} 2\right)^{\wedge} 2\end{array}$ \\
\hline
\end{tabular}

\subsection{Validity and Reliability Criteria}

The criteria of validity and reliability were based on the verification of the algorithm that was done with the development of routines and subroutines generated by exercises that contained or not restrictions of the similar functions generated by Eureqa. We started by testing a simple genetic algorithm with one-variable exercises; the conditions of the algorithm used for each objective function were maintained in 100 generations and a population size of 100 individuals under a crossover probability of $95 \%$ and a mutation probability of $1 \%$. Then test exercises with 2 and 3 variables were performed, thus increasing the complexity of the exercises used; in this case the conditions of the algorithm were varied according to the complexity of each function, but always maintaining the crossover probability of $95 \%$ and the probability of mutation in 1\%. Figure 8 shows the results of the NSGA-II multi-objective genetic algorithm with respect to the "Dominance Fronts" (figure 8a), "Pareto Optimal Fronts" (Figure 8b) and "Unmanaged Solutions" (Figure 8c) Of the final population; this same behavior can be seen in the results reported by [12].

\subsection{Pilot test}

According to the revised literature and to what was established in the previous numerals, it was decided to maintain the probability of crossing and the probability of mutation in $95 \%$ and $1 \%$ respectively; therefore, the size of population $(T)$ and the number of generations ( $\mathrm{G}$ ) developed for the algorithm were established in the pilot under systematic approaches (trial and error), depending on the quality of results (Optima's Solutions Pareto) and computational resource (processing time). Different values and combinations of $T$ and $\mathrm{G}$ were run at a suitable decision criterion for these parameters of 200 for each respectively. The result is shown in figure 9 for 140MXC-530AS a) and 140MXC-560AS b) coating mixes.

\subsection{Final solutions}

Once the number of partial solutions was defined, a new reclassification was carried out in order to obtain a single Optimal Pareto Front for each of the coating mixtures. The best conditions that could be obtained with less standard deviation in the data means that these values do not have much dispersion and that represent a similarity between individuals seen from the condition of parameterization of the technique in the equipment of thermal projection.

Figure 10 shows the graphical results of the Pareto optimal fronts, as a response to the processing of the objective functions for mixing $140 \mathrm{MXC}-530 \mathrm{AS}$ coatings with their 10 possible selections.

Table 9 presents the tabulation of the results of figure 10 for microhardness $(\mathrm{Hv})$ and particle size $(\mu \mathrm{m})$ attributes as a function of projection parameters (input variables), according to the algorithm used. In this case, the selection that should be taken into account to maximize microhardness $(\mathrm{Hv})$ and minimize particle size $(\mu \mathrm{m})$ at the same time would be run \# 6 . Maximum Microhardness $=797.48(\mathrm{Hv})$ and minimum Particle Size $=83.13(\mu \mathrm{m})$, are obtained with the projection parameters: Current $\approx 109.8(\mathrm{~A})$, Primary air pressure $\approx 3.2(\mathrm{bar})$, Secondary air pressure $\approx 3.6(\mathrm{bar})$ and Voltage $\approx 26.5(\mathrm{~V})$. 
Table 9. Final Result - Pareto Front for 140MXC-530AS

\begin{tabular}{|lllllll|}
\hline Current (A) & Primary air pressure (bar) & Secondary air pressure (bar) & Voltage $(\boldsymbol{V})$ & Microhardness $(\mathrm{Hv})$ & $\begin{array}{l}\text { Particle Size } \\
(\mu \mathrm{m})\end{array}$ \\
\hline 114.8 & 3.3 & 3.7 & 29.7 & 741.83 & 80.00 \\
\hline 114.8 & 3.3 & 3.7 & 30.7 & 762.88 & 80.01 \\
\hline 108.7 & 3.3 & 3.6 & 30.9 & 777.09 & 80.01 \\
\hline 109.5 & 3.3 & 3.7 & 31.1 & 782.86 & 80.06 \\
\hline 109.4 & 3.3 & 3.7 & 31.3 & 787.17 & 80.09 \\
\hline 109.8 & 3.2 & 3.6 & 26.5 & 797.48 & 80.13 \\
\hline 109.7 & 3.3 & 3.6 & 32.1 & 799.38 & 80.75 \\
\hline 102.8 & 3.2 & 3.8 & 26.1 & 799.66 & 81.06 \\
\hline 115.1 & 3.3 & 3.8 & 32.4 & 799.86 & 82.66 \\
\hline 109.2 & 3.3 & 3.7 & 31.9 & 799.99 & 83.65 \\
\hline
\end{tabular}

For the mixing 140MXC-560AS coatings, the same selection criteria were considered as for the 140MXC-530AS, Figure 11 shows the graphical results of the Pareto optimal fronts, as a response to the processing of the objective functions for mixing 140MXC-560AS coatings with their 10 possible selections too.

Similarly, table 10 presents the tabulation of the results of figure 11 for microhardness $(\mathrm{Hv})$ and particle size $(\mu \mathrm{m})$ attributes as a function of projection parameters (input variables), according to the algorithm used, Here, the selection that should be taken into account to maximize microhardness $(\mathrm{Hv})$ and minimize particle size $(\mu \mathrm{m})$ at the same time would be run \# 4, Maximum Microhardness $=797,56(\mathrm{Hv})$ and minimum Particle Size $=80,19(\mu \mathrm{m})$, are obtained with the projection parameters: Current $\approx 102,8$ (A), Primary air pressure $\approx 3,2($ bar), Secondary air pressure $\approx 3,8$ (bar) and Voltage $\approx 25,9(V)[19,20]$.

Therefore, tables 9 and 10 indicate the configuration to be made to the thermal projection equipment as projection parameters and the production of the mixtures 140MXC-530As and 140MXC-560AS coatings for the expected attributes.

Table 10. Final Results Parameterization for 140MXC-560AS 


\begin{tabular}{|llllll|}
\hline Current (A) & Primary air pressure (bar) & Secondary air pressure (bar) & Voltage $(\boldsymbol{V})$ & Microhardness $(\mathrm{Hv})$ & $\begin{array}{l}\text { Particle Size } \\
(\boldsymbol{\mu m})\end{array}$ \\
\hline 115.7 & 3.2 & 3.7 & 25.5 & 754.28 & 80.00 \\
\hline 108.7 & 3.3 & 3.6 & 30.9 & 777.09 & 80.01 \\
\hline 109.1 & 3.2 & 3.8 & 26.1 & 795.58 & 80.02 \\
\hline 102.8 & 3.2 & 3.8 & 25.9 & 797.56 & 80.19 \\
\hline 108.9 & 3.2 & 3.8 & 26.2 & 797.93 & 81.04 \\
\hline 103.2 & 3.3 & 3.7 & 32.1 & 799.35 & 81.06 \\
\hline 102.8 & 3.2 & 3.8 & 25.9 & 799.66 & 81.06 \\
\hline 103.6 & 3.2 & 3.7 & 26.1 & 799.79 & 82.61 \\
\hline 115.1 & 3.3 & 3.8 & 32.4 & 799.86 & 82.66 \\
\hline 109.2 & 3.3 & 3.7 & 31.9 & 799.99 & 83.65 \\
\hline
\end{tabular}

\section{Conclusions}

1. The application of the Taguchi model L9 $\left(3^{4-2}\right)$ in the first instance for the production of the mixtures of coatings $140 \mathrm{MC}-530 \mathrm{AS}$ and 140MXC-560AS provided the combination of the projection parameters to perform the minimum of tests (experiments) to be a fractional factorial orthogonal array statistically.

2. Characterization of the coating's mixtures $140 \mathrm{MXC}-530 \mathrm{AS}$ and $140 \mathrm{MXC}-560 \mathrm{AS}$, allowed to establish the optimization conditions (table 6), seeking that the results of the attributes minimize the wear (higher values in the microhardness) and maximize the resistance corrosion (lower values in particle size) of the coatings produced.

3. The use of symbolic regression through the Eureqa Formulize-Desktop program granted objective functions according to the type of model to be configured, in this case the search for the functions with constant values, basic mathematical and trigonometric operations and exponential expressions were parameterized which can be extended depending on the computing resource.

4. From the point of view of the projection parameters current $(A)$, voltage $(V)$, primary air pressure (bar) and secondary air pressure (bar) which encompass discrete and continuous process variables, it was established that these input variables derived in the quality of the coatings displayed in the attribute values selected for this work and to work it as a solution considered mixed optimization problem.

5. In the criteria of validity and reliability it was possible to establish that the algorithm converges towards the global optimum depending on the quality of the run, the conditions of restriction and the configuration conditions of the same.

6. The appropriate number of generations $(T)$ and population (G) was 200 for each one respectively, since it was possible to visualize in the feasible space analysis of solutions and in the pilot test according to the computational resource.

7. The individuals closest to the optimization condition established by decision criterion are between 799 and 800 (Hv) for the microhardness attribute and 80 and $90(\mu \mathrm{m})$ for the particle size attribute.

8. In order to obtain the attribute values mentioned above in the production of the mixtures of $140 \mathrm{MXC}-530 \mathrm{AS}$ and $140 \mathrm{MXC}-560 \mathrm{AS}$ coatings, the projection parameters must be set at level 1 for the current and for the minimum voltage at 3 or at maximum at 4; these two parameters are considered as discrete variables (figure 4) in the configuration of the projection equipment.

9. In the case of air pressures (continuous variables), for the mixture $140 \mathrm{MXC}-530 \mathrm{AS}$, coatings the values of the primary air pressure must be set at 3,2 (bar) the minimum and 3,3 (bar) the maximum and for the secondary air pressure the minimum at 3,6 (bar) and the maximum at 3,8 (bar); and for mixture 140MXC-560AS coatings the values of the primary air pressure and secondary air pressure are the same as the mixture $140 \mathrm{MXC}-530 \mathrm{AS}$ coatings.

\section{Declarations}


The authors sincerely thank the members of the DETECAL and AFIS research groups for their critical discussion and reading during manuscript preparation, To the engineer Eli Rafael Díaz of the Corporation of Science and Technology for the Development of the Naval, Maritime and River Industry of Colombia "COTECMAR".

\section{Authors' Contributions}

HR was in charge of the whole trial and wrote the manuscript; AG worked in the scheme of the optimization model; OL and DA worked obtaining objective functions in Eureqa Formulize-Desktop and coding genetic algorithm for MATLAB. All authors read and approved the final manuscript.

\section{Funding}

Supported by National Program in Research, Development and Innovation $(R+D+I)$ Colciencias: Recovery of metal parts by thermal spraying project Colombia.

\section{Competing Interests}

The authors declare that they have no competing interests.

\section{Author Details}

1 Universidad Libre, Bogotá Headquarters, Faculty of Engineering, Mechanical Engineering Program, Bosque Popular Campus, Av,Cra 70 No 53-40, Colombia.

2 National University of Colombia, Bogotá Headquarters, Faculty of Engineering, Mechanical and Mechatronic Engineering Program, Av,Cra, 30 St 45, Colombia.

3 National Learning Service - SENA, Regional Capital District, Materials and Testing Center - CME, Av, Cra 30 No $17 \mathrm{~B} 25$ south, Colombia.

\section{References}

1. Tucker, R, C, (2002), Thermal Spray Coatings, Metals Handbook, Volume 5: Surface Engineering, Praxair Surface Technologies, Inc, (pp 1450), United States of America: ASM International.

2. Sulzer, (2013), Sulzer Metco, An Introduction to Thermal Spray, Issue 4, (pp 6). https://www,upc,edu/sct/es/documents_equipament/d_324_id-804-2,pdf, Accessed 16 September 2019

3. Chapra, S,C, \& Raymond, P,C, (2007), Métodos numéricos para ingenieros, Mexico, D,F, McGraw-Hill.

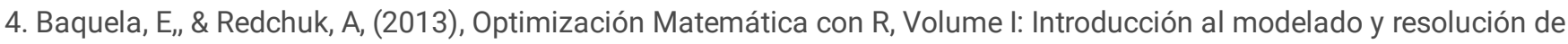
problemas, Spain: Editor Bubok Publishing S,L.

5. Davis, J, R, (2004), Handbook of Thermal Spray Technology, Davis \& Associates (Ed,), Introduction to Thermal Spray Technology and Surface Science (pp,1-10), United States of America: ASM International, Thermal Spray Society.

6. Rojas, H, F, Olaya, J, J, \& Molina, C, A, (2016), Caracterización morfológica de los recubrimientos 140MXC-530AS y 140MXC560AS usando la técnica de proyección térmica por arco eléctrico, Journal of Engineering, Research and Technology, 17, 1-13.

7. Rojas, H, F, Olaya, J, J,, \& Morales, J, A, (2012), Una aproximación a la tecnología de proyección térmica, AVANCES Journal: Engineering Research, 9, 60-71.

8. Luna, O, E, Rojas, H, F, \& Sánchez, H, G, (2014), Contextualización de la técnica de aspersión por arco eléctrico, Journal of Military Engineers, 5, 85-98.

9. Romero, C, (1993), Teoría de la decisión multicriterio: conceptos, técnicas y aplicaciones, Volume 144 of University Alliance texts, Spain: Alianza editorial.

10. Groşan, C, \& Dumitrescu, D, (2002), A comparison of multiobjective evolutionary algorithms, Journal of University Act: Apulensis, $4,60-72$.

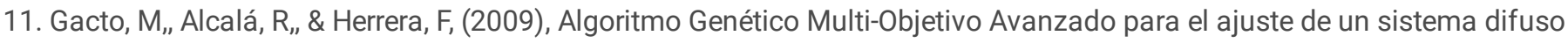
aplicado al Control de Sistemas de Ventilación, Calefacción y Aire Acondicionado, Conference Paper: Proceedings of the 
Congreso Español sobre Metaheurísticas, Algoritmos Evolutivos y Bioinspirados (MAEB), 595-602.

12. Deb, $K_{\text {„ }}$ Pratap, A, Agarwal, $S$, \& Meyarivan, T, (2002), A fast and elitist multiobjective genetic algorithm: NSGA-II, Evol, Comput, IEEE Trans, On, 6, 182-197.

13. Mendoza, J, E, Villaleiva, L, A, Castro, M, A, \& Lopez, E, A, (2009), Multi-objective Evolutionary algorithms for decision-making in reconfiguration problems applied to the electric distribution networks, Journal of Studies in Informatics and Control, 18 (4), 325 336.

14. Moreno, R, (2007), Programación genética: La regresión simbólica, ENTRAMADO Journal, 3 (1), 76-85,

15. Ramos, A, Sánchez, P, Ferrer, J, Barquín, J, \& Linares, P, (2010), Modelos matemáticos de optimización, Technical publications, doi: icai,upcomillas,es/intro_simio,htm.

16. Popov, A, (2005), Genetic Algorithms for optimization: Programs for Matlab user manual, Hamburg: TU-Sofia.

17. Azketa, E, Gutierrez, J, Di Natale, M, Almeida, L, \& Marcos, M, (2013), Permutational genetic algorithm for the deployment and scheduling of distributed real time systems, Iberoamerican Journal of Industrial Automatics and Informatics, 10 (3), 344-355.

18. Meneses, C, \& Echeverry, M, (2007), Optimización multiobjetivo usando un algoritmo genético y un operador elitista basado en un ordenamiento no-dominado (NSGA-II), Scientia et Technica Journal, 8 (35), 175-180.

19. Rojas, H, F, Cueca, F, A, Ibarra, G, C, \& Olaya, J, J, (2017), Aspersión Térmica por Arco Eléctrico: Influencia de los parámetros de proyección en la morfología de las partículas a diferentes distancias de aplicación, Spain: Spanish Academic Publishing.

20. Rojas, H, F, Olaya, J, J, Guzman M, A, \& Beltran, N, A, (2019), Semilleros: Eslabones para la investigación, Fondo de Publicaciones de la Universidad Libre, Análisis del desgaste abrasivo al recubrimiento 140MXC-560AS producido mediante proyección térmica por arco eléctrico (pp, 55-77), Colombia: AF\&M Producción Gráfica S.A.S.

\section{Figures}

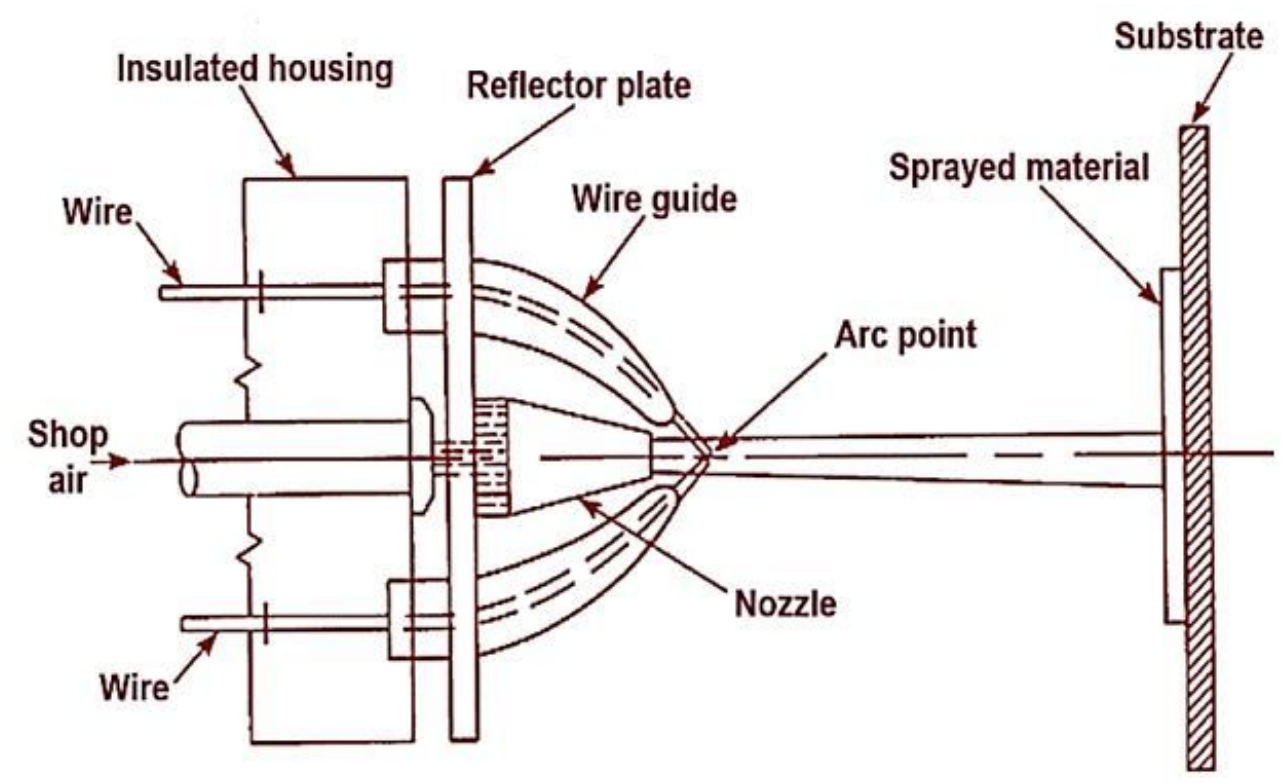

Figure 1

Typical electric - arc spray device. Adapted from [1] 


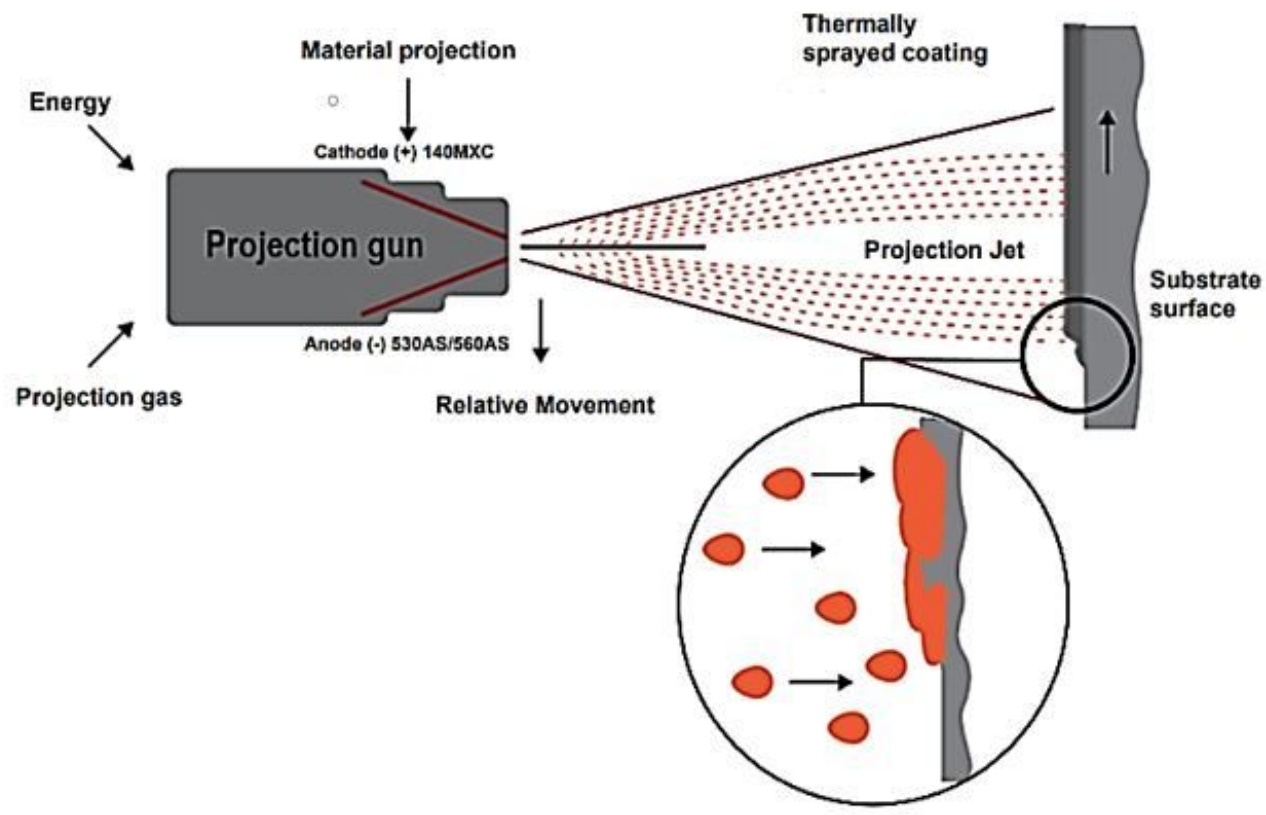

\section{Figure 2}

Principle of electric wire arc spraying process. Adapted from [2] 


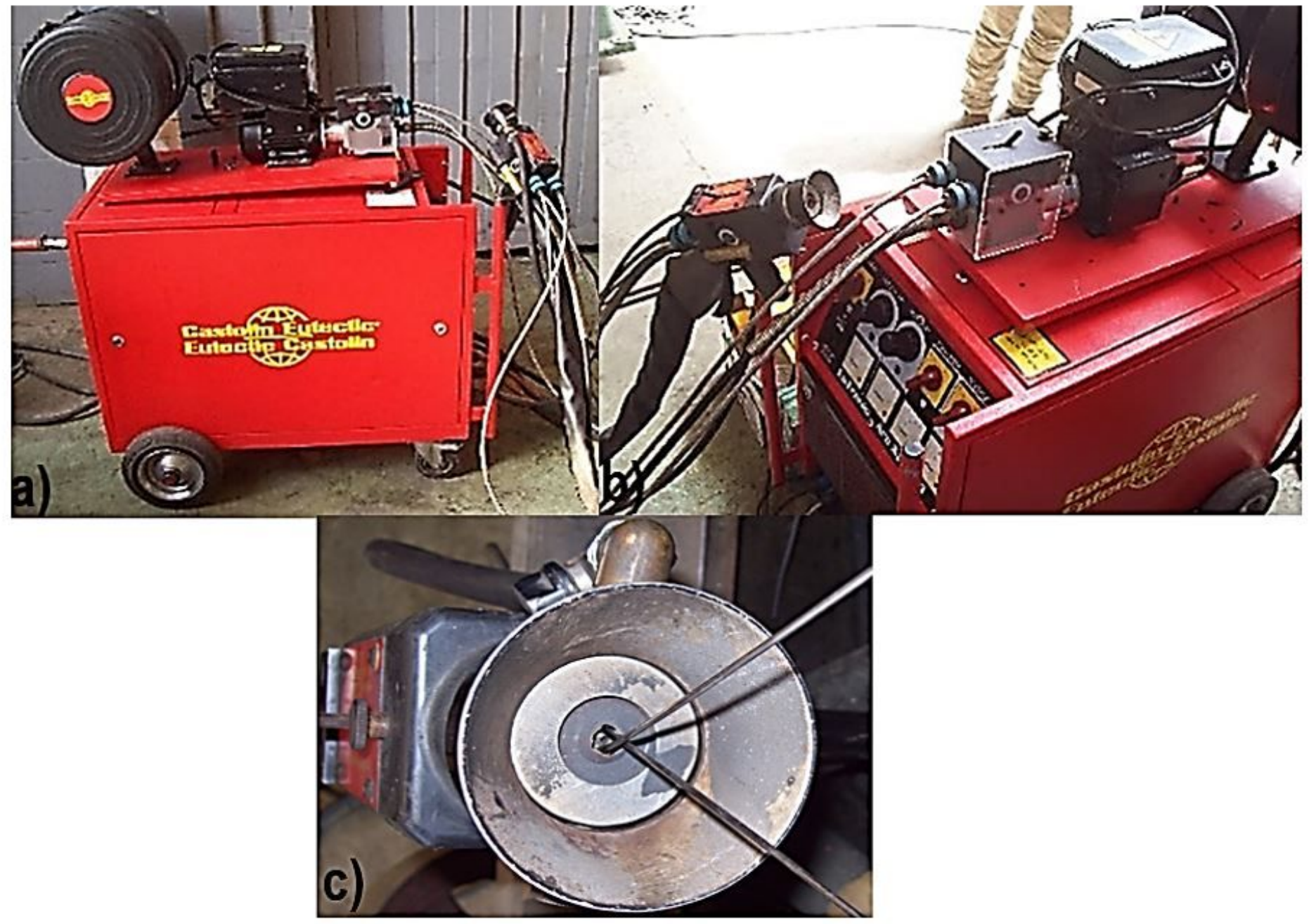

Figure 3

Thermal projection equipment System Eutectic / Eutronic Arc Spray 4. With permission from COTECMAR

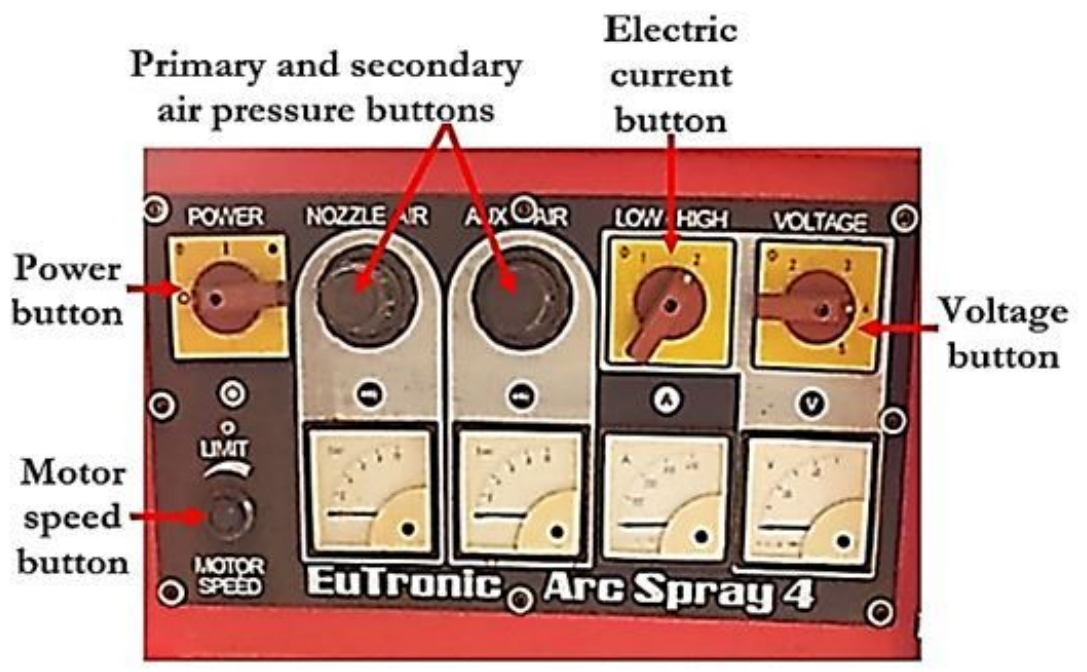

Figure 4

Eutectic - Eutronic Arc Spray 4 - Unit operating console. With permission from COTECMAR 


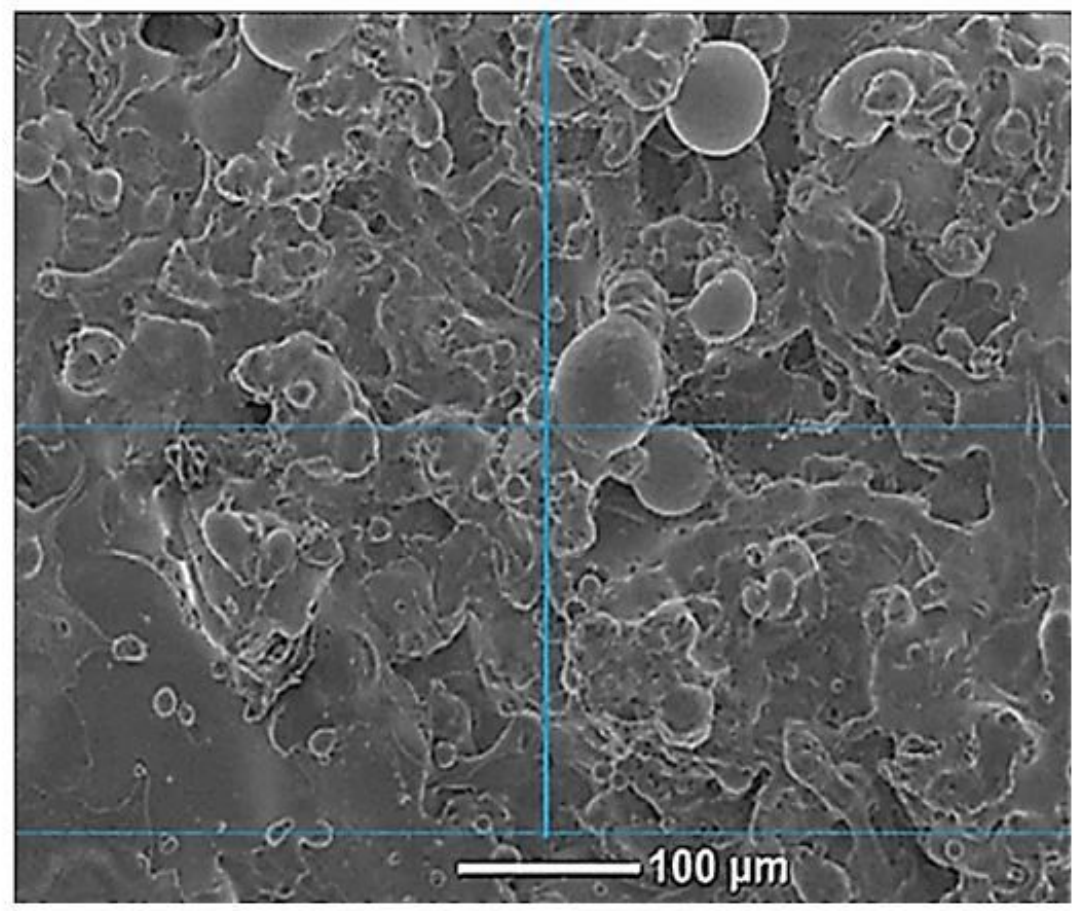

Figure 5

Determination of particle size $(\mu \mathrm{m})$

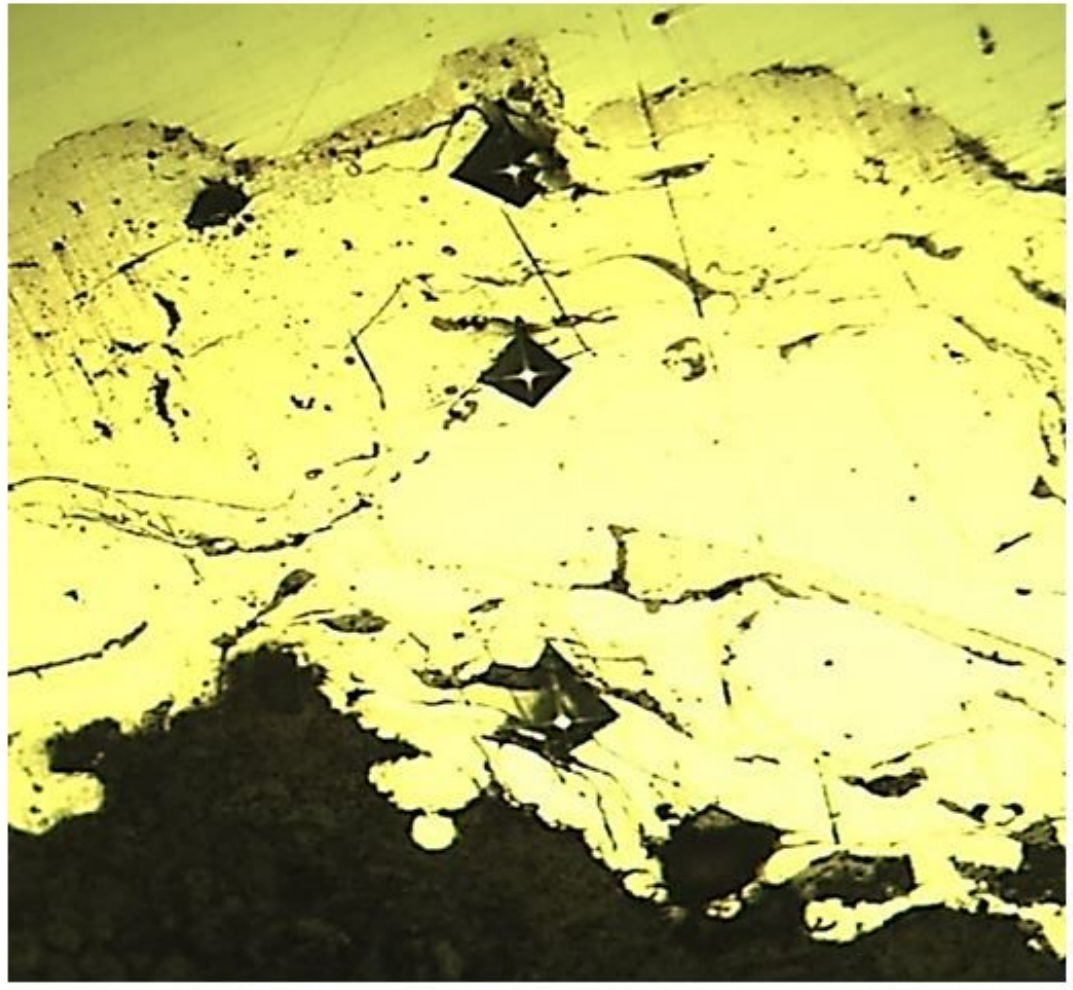

Figure 6

Microhardness test (Hv) 


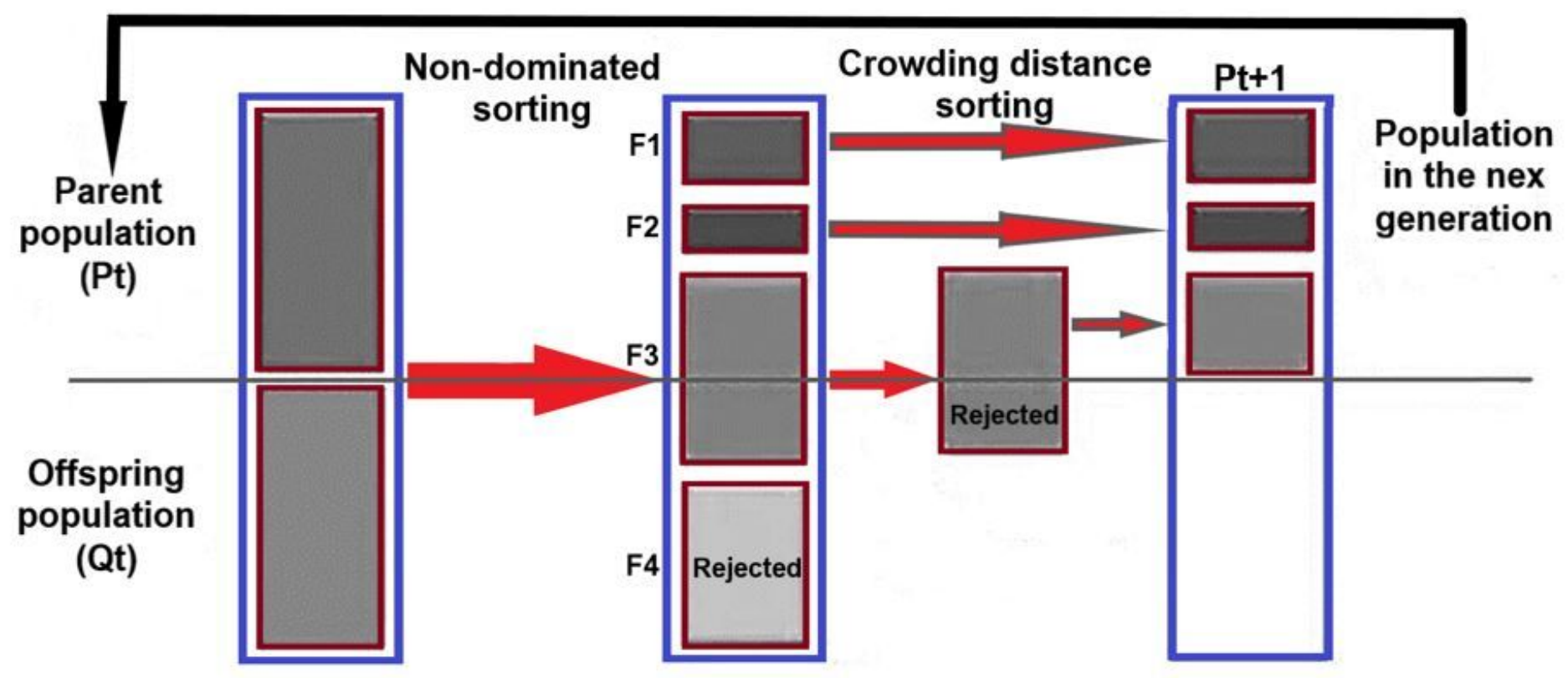

Figure 7

NSGA-II Procedure to determine new population. Adapted from [18] 

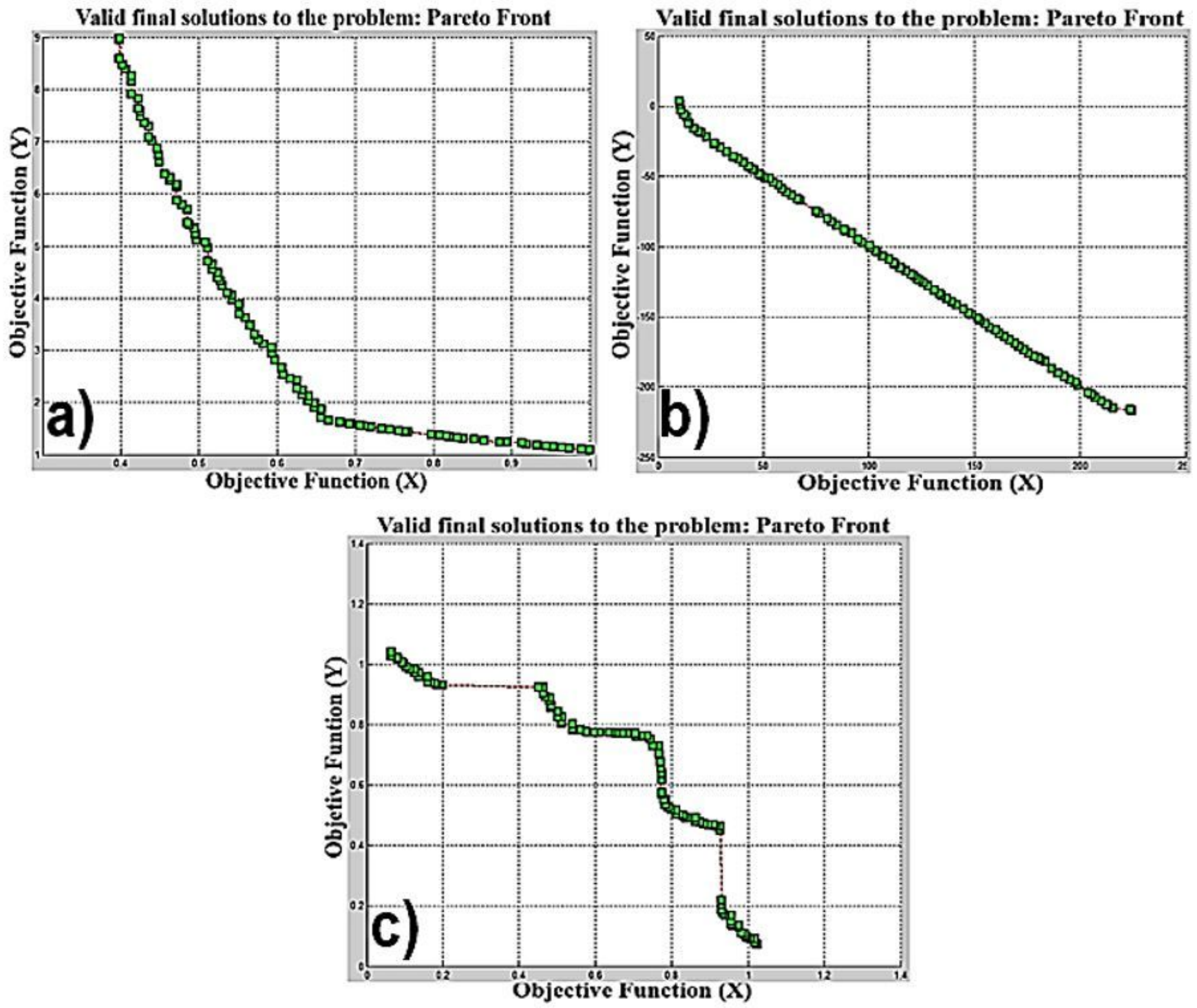

Figure 8

Contrast between results of problems 

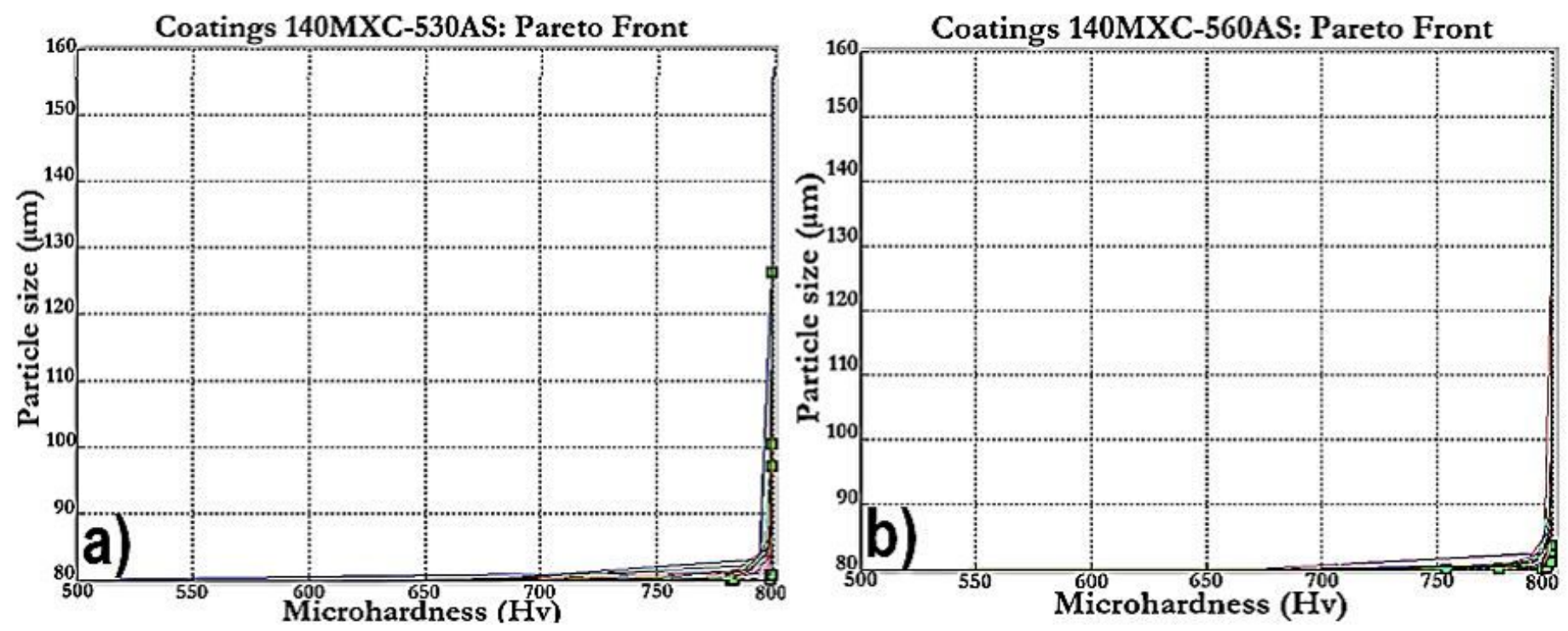

Figure 9

Race results with Generation $(G)=200$ and Population size $(T)=200$

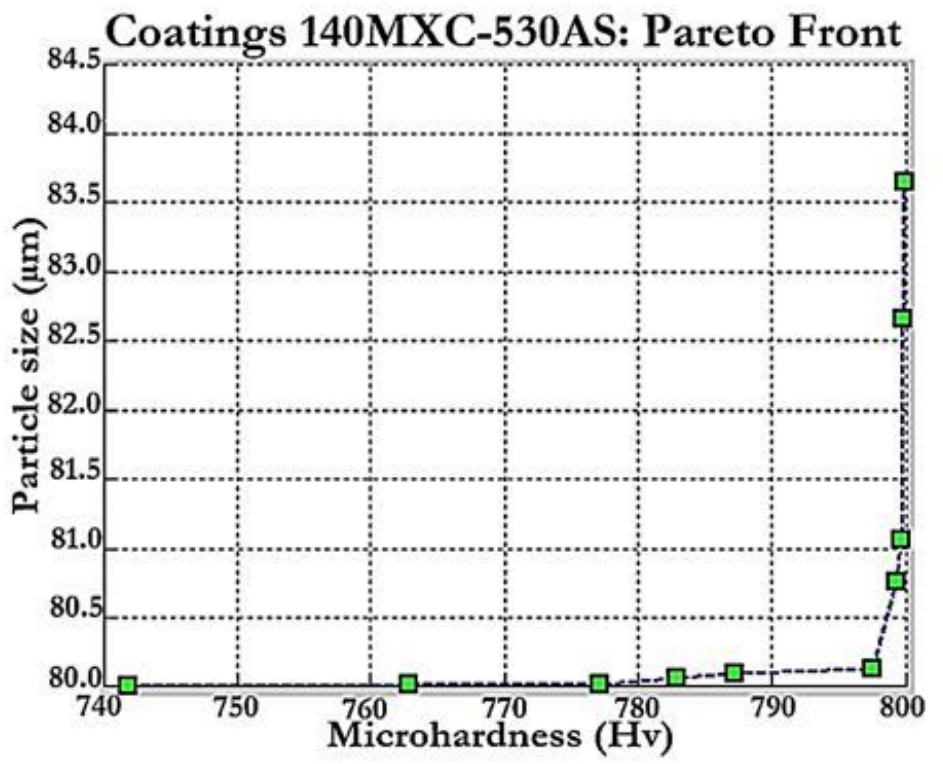

Figure 10

Final Pareto Front Graphic for 140MXC-530AS 


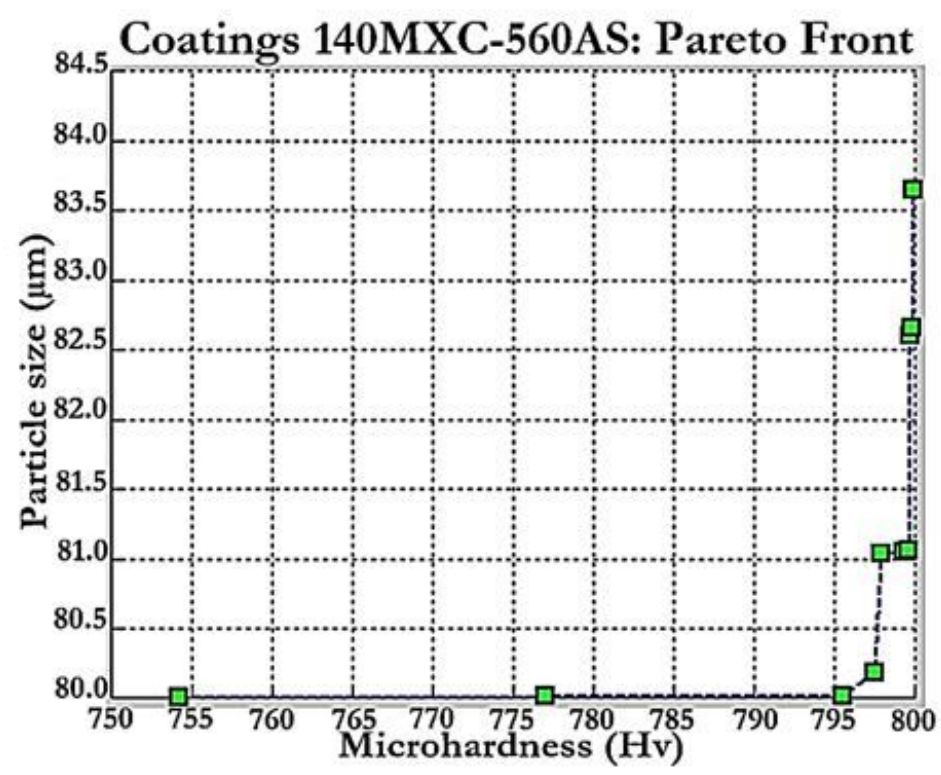

Figure 11

Final Pareto Front Graphic for 140MXC-560AS 